\title{
Influence of High BMI on Functional Outcome After Total Hip Arthroplasty
}

\author{
André Busato • Christoph Röder • \\ Sylvia Herren • Stefan Eggli
}

Received: 9 May 2007 / Accepted: 27 May 2007 / Published online: 28 March 2008

(C) Springer Science + Business Media, LLC 2007

\begin{abstract}
Background High body mass index (BMI) is associated with diseases of the hip joint and subsequent total hip arthroplasty (THA). Less is known about the effects of BMI on the functional postoperative status after THA in obese patients. The purpose of this study was therefore to quantify the role of high preoperative BMI on long-term pain status and functional outcome after THA.

Methods In a multi-center cohort, study data of 20,553 primary THAs (18,968 patients) and 43,562 postoperative clinical examinations were analyzed for a follow-up period of up to 15 years. Patients were classified into three BMI groups (normal weight $<25 \mathrm{~kg} / \mathrm{m}^{2}$, overweight 25 to $<30 \mathrm{~kg} / \mathrm{m}^{2}$, and obese $\geq 30 \mathrm{~kg} / \mathrm{m}^{2}$ ), and pain status and functional outcome were compared accordingly.

Results High preoperative BMI is associated to an almost perfect dose-effect relationship with decreased ambulation during a follow-up period of 15 years, but pain relief of THA is equally efficient for all BMI groups.

Conclusion Overweight and obesity are modifiable risk factors that may warrant physicians giving recommendations to patients before or after THA, to improve postoperative functional outcome quality.
\end{abstract}

Keywords Hip replacement - Arthroplasty .

Body mass index $\cdot$ Obesity $\cdot$ Outcome research

A. Busato $\cdot$ C. Röder $(\bowtie) \cdot$ S. Herren

Institute for Evaluative Research in Orthopaedic Surgery,

University of Berne, Berne, Switzerland

e-mail: Christoph.Roder@insel.ch

S. Eggli

Dept. of Orthopaedic Surgery, University of Berne, Inselspital, CH-3010 Berne, Switzerland

e-mail: stefan.eggli@insel.ch

\section{Introduction}

Reducing or eliminating pain and restoring physical function are the primary goals of total hip arthroplasty (THA). Knowledge of prognostic factors associated with postoperative outcomes is therefore an important element when surgeons are advising their patients on the risks and benefits of THA [1,2]. Factors that can be modified either by patients or surgeons to favor better outcomes are of particular interest in this context. High body weight has been associated with negative [3, 4] and positive [5] outcomes of THA. However, quantitative and long-term estimates of such effects are currently lacking. The purpose of this study was to quantify the role of high preoperative body mass index (BMI), as a measure of relative body weight, on longterm pain status and functional outcome after THA.

\section{Patients and Method}

The study was designed as a cohort study based on data from the total hip registry of the Maurice E. Müller Foundation in Berne, Switzerland, and on a comparable database maintained at the Sunnybrook and Women's College Health Sciences Centre in Toronto, Canada. These combined data sets represent one of the largest databases with pre-, intra-, and postoperative clinical data on patients with THA. The data collection was started in 1965 and is still ongoing. Data are collected using optically readable code sheets according to the standards of the International Documentation and Evaluation System (IDES) [6]. The code sheets include information on demographics, pre- and postoperative functional status, pain levels of patients, surgical procedures, implant characteristics, and postoperative implant status with reference to component loosening. Additional 
information is available on implants revised because of component failure. All data have been collected in multiple hospitals located in various countries on a voluntary basis.

Baseline information of 18,968 patients older than 20 years with complete preoperative data sets regarding pain status, walking time without support, hip flexion range, and preoperative BMI were evaluated. Primary THAs were performed between 1965 and 2003 in 42 European and one Canadian hospital. Follow-up data up to postoperative year 15 totaled 43,562 postoperative clinical examinations. Bilateral THA was performed in $7.7 \%$ of all THAs. Patients with radiographic signs of loose prosthetic components, as well as revision operations, were excluded from the comparative analysis.

Preoperative BMI was calculated for all patients, based on weight and body height at admission (calculated as weight in kilograms divided by the body height in meters squared). Postoperative pain status and functional outcome was compared for BMI groups of patients classified according to National Institutes of Health (Bethesda, MD 20892, USA) as underweight: $<18.5 \mathrm{~kg} / \mathrm{m}^{2}$; normal weight: 18.5 to $<25.0 \mathrm{~kg} / \mathrm{m}^{2}$; overweight: 25.0 to $<30.0$; obese I: 30.0 to $<35.0 \mathrm{~kg} / \mathrm{m}^{2}$; obese II: 35.0 to $<40.0 \mathrm{~kg} / \mathrm{m}^{2}$; and as extremely obese: $\geq 40 \mathrm{~kg} / \mathrm{m}^{2}$. Outcomes were compared over the entire follow-up period, with formal statistical tests at years 3, 6, 9, and 12 after THA. For purposes of visualization, results were also displayed graphically.

All outcome items were recorded on a ordered categorized scale:

- Hip pain: none, mild, moderate, severe, and intolerable. Walking time without support: $>60,31-60,10-30$, $<10 \mathrm{~min}$, and none. Stair climbing: normal, assisted, two feet on each step, other method, or not possible. Hip flexion range: $>90,71-90,30-70,<30^{\circ}$, stiff. Difficulties putting on shoes and socks: none, slight, extreme, unable.

- Hip pain, walking time without support, and hip flexion range are mandatory fields in IDES forms; that is, forms with data missing in these fields cannot be entered into the database. Stair climbing and difficulties putting on shoes/socks are not defined as mandatory fields. Data for these indicators were therefore not always complete. Nonetheless, there were 39,519 follow-ups where stair-climbing capabilities were recorded. Similarly, 16,319 follow-ups provided information about the degree of difficulties with putting on shoes and socks.

For every follow-up year and for each indicator, the proportion of patients with the most favorable outcome was analyzed as a binary variable, i.e., the proportion of patients with no hip pain, with walking time without support $>60$ min, with hip flexion range $>90^{\circ}$, and with capability for normal stair climbing and putting on shoes and socks in a normal way.

Statistical analysis included initial descriptive procedures for continuous data with the calculation of means with 95\% confidence intervals (CI95), medians, and quartiles. Categorical data were described using proportions with CI95. Gender- and diagnosis-adjusted associations between age and BMI at THA were analyzed using linear models. For graphical comparisons of outcomes, proportions were directly standardized with reference to gender, age group, and diagnosis. Age groups were defined based on quartiles of the observed data (first quartile $=58.5$ years, median $=$ 66.0 years, third quartile $=73.1$ years), and diagnoses were categorized, according to IDES definitions, into osteoarthritis, dysplasia, inflammatory arthritis, fracture, and other diagnoses (osteonecrosis, Paget's disease, post-septic arthritis, tumors). The statistical differences of pain and functional outcomes between BMI groups were assessed, using multivariate logistic regression separately for followup years $3,6,9$, and 12 . The outcome variables were the proportions as described above, and the explanatory variables included BMI groups, gender, age in years at THA, diagnosis, and clinic where THA was performed. Relative risks for the best outcome across BMI groups were calculated with the normal weight group as the reference group (Table 3). Bonferroni adjustments were used to address the problem of multiple testing. Preliminary analyses of patient distribution across BMI groups indicated low frequencies in groups with extreme BMI (Table 1). The BMI classification was therefore simplified for statistical
Table 1 Distribution of BMI classes at primary THA

Data derived from 18,968 patients (7.7\% bilateral THA).

\begin{tabular}{lccc}
\hline BMI Group & Frequency & Percent & $95 \%$ Confidence limits \\
\hline Underweight $\left(<18.5 \mathrm{~kg} / \mathrm{m}^{2}\right)$ & 354 & 1.7 & $1.5-1.9$ \\
Normal weight $\left(18.5\right.$ to $\left.<25.0 \mathrm{~kg} / \mathrm{m}^{2}\right)$ & 7,469 & 36.3 & $35.6-37.1$ \\
Overweight $\left(25.0\right.$ to $\left.<30.0 \mathrm{~kg} / \mathrm{m}^{2}\right)$ & 8,978 & 43.7 & $42.9-44.4$ \\
Obese $\left(\geq 30.0 \mathrm{~kg} / \mathrm{m}^{2}\right)$ & 3,752 & 18.3 & $17.7-18.8$ \\
Obese I $\left(30.0\right.$ to $\left.<35.0 \mathrm{~kg} / \mathrm{m}^{2}\right)$ & 3,078 & 15.0 & $14.4-15.5$ \\
Obese II $\left(35.0\right.$ to $\left.<40.0 \mathrm{~kg} / \mathrm{m}^{2}\right)$ & 559 & 2.7 & $2.5-3.0$ \\
Extreme obese $\left(\geq 40 \mathrm{~kg} / \mathrm{m}^{2}\right)$ & 115 & 0.6 & $0.5-0.7$ \\
Total & $20,553 *$ & 100.00 & \\
\end{tabular}


Table 2 Distribution of gender-adjusted age (least square means) in years at THA across diagnoses and BMI groups

\begin{tabular}{|c|c|c|c|c|c|c|c|c|c|}
\hline \multirow[t]{2}{*}{ Diagnosis } & \multicolumn{3}{|c|}{ BMI <25 (normal) } & \multicolumn{3}{|c|}{ BMI 25 to $<30$ (overweight) } & \multicolumn{3}{|c|}{$\mathrm{BMI} \geq 30$ (obese) } \\
\hline & $N$ & LSM & $95 \% \mathrm{CI}^{\mathrm{a}}$ & $N$ & LSM & $95 \% \mathrm{CI}^{\mathrm{a}}$ & $N$ & LSM & $95 \% \mathrm{CI}^{\mathrm{a}}$ \\
\hline Osteoarthritis & 5,296 & 67.4 & $67.2-67.7$ & 7,241 & 60.0 & $58.5-61.5$ & 3,139 & 64.9 & $63.5-66.4$ \\
\hline Dysplasia & 972 & 66.7 & $66.5-66.9$ & 634 & 53.9 & $52.6-55.2$ & 221 & 60.1 & $57.4-62.8$ \\
\hline Inflammatory arthritis & 464 & 65.6 & $65.2-65.8$ & 266 & 59.6 & $57.9-61.2$ & 55 & 59.5 & $58.4-60.6$ \\
\hline Fracture & 544 & 55.9 & $55.1-56.7$ & 332 & 61.9 & $58.3-65.5$ & 94 & 60.7 & $59.5-61.8$ \\
\hline Other & 548 & 59.0 & $58.1-59.9$ & 504 & 62.5 & $61.4-63.7$ & 243 & 60.0 & $58.3-61.6$ \\
\hline Overall & 7,824 & 60.5 & $60.2-60.8$ & 8,977 & 60.7 & $60.4-61.0$ & 3,752 & 59.6 & $59.2-60.0$ \\
\hline
\end{tabular}

a $95 \%$ confidence limits

analysis as normal weight $<25 \mathrm{~kg} / \mathrm{m}^{2}$, overweight 25 to $<30 \mathrm{~kg} / \mathrm{m}^{2}$, and obese $\geq 30 \mathrm{~kg} / \mathrm{m}^{2}$. Confidence interval calculation and statistical analyses of differences accounted for nonindependence of observations in patients with bilateral THA, using the Taylor expansion method. For all statistical tests, a level of significance was set at 0.05 throughout the paper, and SAS 9.1 (SAS Institute, Inc., Cary, NC, USA) was used for all calculations.

\section{Results}

Complete preoperative data and follow-up examinations up to year 15 amounted to 64,115 records. The distribution of the initial BMI classes at THA is given in Table 1. The respective numbers of observations in each aggregated BMI group before THA and for follow-up years 3, 6, 9, and 12 are given in Tables 2 and 3 .

A total of 10,138 female (53.5\%) and 8,830 male (46.5\%) patients were included in the study. The average age at THA was 64.8 years $(\mathrm{CI} 95=65.7-65.0)$, male patients were on average 64.1 years old $(\mathrm{CI} 95=63.9-64.3)$, and females were 65.5 years $(\mathrm{CI} 95=65.3-65.7)$. Average BMI at THA was $26.49($ CI95 $=26.42-26.55$; median $=26.2$; first quartile $=$ 23.7, third quartile $=29.0$ ). The BMI of female patients was 26.04 (CI95 $=25.94-26.14)$; the BMI of male patients was $26.99(\mathrm{CI} 95=26.91-27.08)$ and significantly higher than in females. No significant difference in BMI was observed between patients with uni- and bilateral THA. The distribution of the main diagnoses at THA was osteoarthritis in $76.3 \%$ of cases, dysplasia in $8.9 \%$, inflammatory arthritis in $3.8 \%$, fractures in $4.7 \%$, and other diagnoses in $6.3 \%$ of cases (Table 2). The gender-adjusted age at THA, calculated as least square means obtained from a linear model, was significantly decreased in obese patients for osteoarthritis, dysplasia, and inflammatory arthritis, but not for fractures (Table 2). The effect of BMI on age at THA was, however, not consistent and nonlinear across diagnostic groups.

The proportions of patients without hip pain at postoperative years 3, 6, 9, and 12 are given in Table 3 . The results

Table 3 Percentage ( $\pm 95 \%$ confidence limits) of patients without hip pain and with best functional status across BMI groups for follow-up years-3, 6, 9, and 12

\begin{tabular}{|c|c|c|c|c|c|c|c|c|c|c|c|c|}
\hline \multirow{2}{*}{$\begin{array}{l}\text { Follow-up } \\
\text { year } \\
3\end{array}$} & \multirow{2}{*}{$\begin{array}{c}\text { BMI } \\
<25\end{array}$} & \multirow{2}{*}{$\begin{array}{l}\text { Number }^{\mathrm{a}} \\
2,537\end{array}$} & \multicolumn{2}{|c|}{ No hip pain } & \multicolumn{2}{|c|}{$\begin{array}{l}\text { Walking time } \\
\text { without support } \\
>60 \text { min }\end{array}$} & \multicolumn{2}{|c|}{$\begin{array}{l}\text { Normal stair } \\
\text { climbing }\end{array}$} & \multicolumn{2}{|c|}{$\begin{array}{l}\text { Hip flexion } \\
\text { range }>90^{\circ}\end{array}$} & \multicolumn{2}{|c|}{$\begin{array}{l}\text { Normal tying } \\
\text { shoes }\end{array}$} \\
\hline & & & 79.4 & $77.8-81.0$ & 63.8 & $62.0-65.6$ & 85.0 & $83.6-86.5$ & 80.9 & $79.3-82.4$ & 75.1 & $72.1-78.2$ \\
\hline & $25-30$ & 2,884 & 79.3 & $77.7-80.8$ & 58.8 & $57.0-60.6$ & 81.6 & $80.1-83.2$ & 77.8 & $76.2-79.4$ & 73.5 & $70.7-76.4$ \\
\hline & $>30$ & 1,150 & 78.9 & $76.5-81.4$ & $49.7^{b}$ & $46.9-52.4$ & $75.1^{\mathrm{b}}$ & $72.6-77.6$ & $73.1^{\mathrm{b}}$ & $70.5-75.8$ & $61.2^{\mathrm{b}}$ & $56.5-66.0$ \\
\hline \multirow[t]{3}{*}{6} & $<25$ & 1,492 & 79.5 & $77.5-81.6$ & 57.9 & $55.5-60.4$ & 77.8 & $75.8-79.9$ & 78.4 & $76.3-80.5$ & 74.4 & $71.1-77.6$ \\
\hline & $25-30$ & 1,933 & 80.4 & $78.6-82.2$ & 54.6 & $52.5-56.7$ & 72.9 & $70.9-74.9$ & 76.9 & $75.0-78.9$ & 69.9 & $67.1-72.8$ \\
\hline & $>30$ & 828 & 78.9 & $76.1-81.8$ & $44.5^{\mathrm{b}}$ & $41.3-47.8$ & $64.7^{\mathrm{b}}$ & $61.5-68.0$ & $70.2^{\mathrm{b}}$ & $67.1-73.3$ & $64.1^{\mathrm{b}}$ & $59.7-68.5$ \\
\hline \multirow[t]{3}{*}{9} & $<25$ & 500 & 75.5 & $71.7-79.3$ & 49.6 & $45.3-53.9$ & 69.3 & $65.2-73.4$ & 77.3 & $73.5-81.1$ & 68.7 & $62.9-74.4$ \\
\hline & $25-30$ & 611 & 74.2 & $70.6-77.7$ & 44.4 & $40.8-48.0$ & 65.7 & $61.9-69.5$ & 72.7 & $69.0-76.3$ & 66.0 & $60.2-71.8$ \\
\hline & $>30$ & 199 & 76.5 & $69.8-83.2$ & $38.3^{\mathrm{b}}$ & $31.9-44.7$ & $54.8^{\mathrm{b}}$ & $47.4-62.2$ & 74.6 & $68.7-80.5$ & $50.3^{b}$ & $41.3-59.3$ \\
\hline \multirow[t]{3}{*}{12} & $<25$ & 158 & 74.6 & $67.0-82.2$ & 45.3 & $37.3-53.4$ & 63.4 & $54.5-72.4$ & 69.3 & $61.2-77.4$ & 62.9 & $53.0-72.8$ \\
\hline & $25-30$ & 152 & 74.4 & $67.1-81.6$ & 42.0 & $36.1-47.9$ & 59.2 & $51.6-66.9$ & 60.6 & $52.4-68.8$ & 57.5 & $47.5-67.5$ \\
\hline & $>30$ & 52 & 81.0 & $71.2-90.8$ & $22.5^{\mathrm{b}}$ & $15.5-29.4$ & 47.3 & $33.4-61.3$ & 80.9 & $79.3-82.4$ & 36.8 & $27.9-45.8$ \\
\hline
\end{tabular}

\footnotetext{
${ }^{\text {a }}$ Sample size for hip pain, walking time without support, and hip flexion range (mandatory fields in the IDES sheets).

${ }^{\mathrm{b}}$ Significant difference $\left(p<0.05\right.$, multivariate logistic regression) from the normal BMI group $\left(<25 \mathrm{~kg} / \mathrm{m}^{2}\right)$.
} 
Fig. 1 Standardized proportions of patients with walking time without support $>60 \mathrm{~min}$

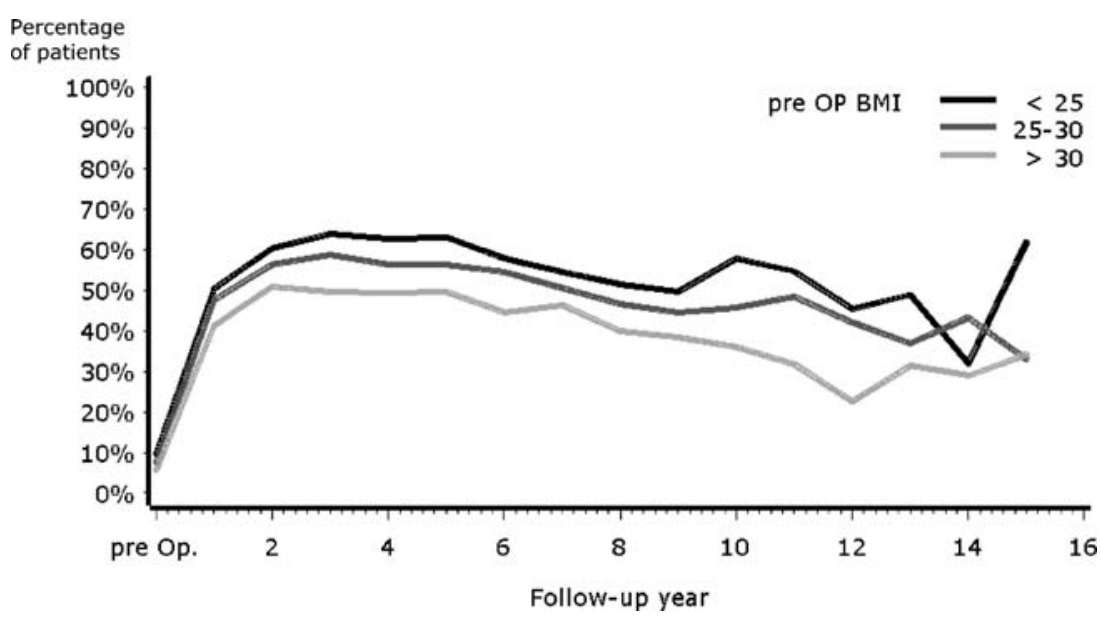

indicate no significant differences between BMI groups for postoperative pain for the entire follow-up period.

\section{Walking Time Without Support}

The proportions of patients capable of walking more than $1 \mathrm{~h}$ at postoperative years $3,6,9$, and 12 are given in Table 3. The standardized proportions across preoperative BMI groups and follow-up time are shown as percentages in Fig. 1. The highest prevalence of cases with the best walking capacity was observed during postoperative years 3-6. Compared to normal weight patients $(\mathrm{BMI}<25)$, obese patients $(\mathrm{BMI}>30)$ had consistently poorer walking capacities. Statistically significant differences between the normal and obese group were observed up to postoperative year 12. The differences in walking time between groups appeared parallel up to year 10 after THA. Postoperative differences in the proportions of patients capable of walking more than $1 \mathrm{~h}$ between these two BMI groups were in the range of $9-21 \%$. Overweight patients also had consistently lower walking capacities. Differences with the normal weight group were, however, not significant for any of the follow-up years $3,6,9$, and 12 .

The crude and standardized data for ascending and descending stairs are given in Table 3 and Fig. 2. The proportion of patients without any impairment in walking up stairs reached its peak during years 2-4 after THA and declined almost in parallel for all BMI groups. The differences in the proportions were significant between the obese and the normal weight group. Similarly consistent but not significant differences were observed between the overweight and the normal weight group.

The crude proportion of patients with hip flexion range greater than $90^{\circ}$ is shown in Table 3. Hip flexion range was above $90^{\circ}$ for more than $70 \%$ of all patients in all BMI groups, up to postoperative year 6 , but the number of cases with the best flexion range in the obese group was significantly lower than in the normal weight group. Consistent differences were seen between overweight and normal weight groups, but they were not statistically significant.
Fig. 2 Standardized proportions of patients capable of normal stair climbing

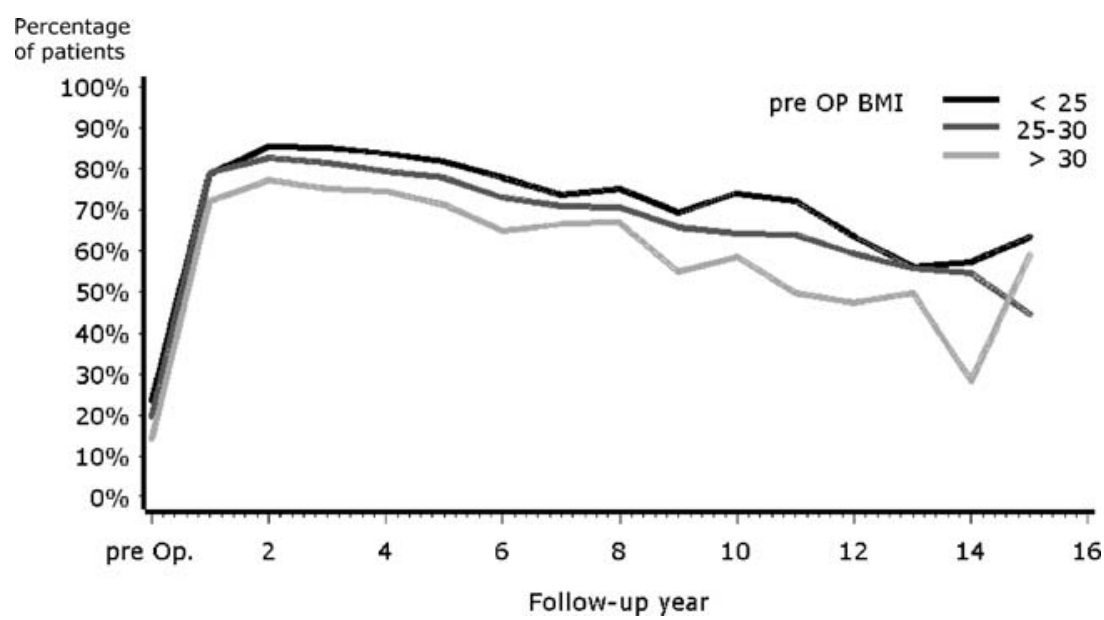




\section{Discussion}

There is high evidence that obesity is a risk factor for osteoarthritis and subsequent THA [7-11]. In addition, obesity was also identified as a risk factor for intra- and postoperative complications in THA [12]. However, there is little information available on the effects of preoperative obesity on postoperative pain and functional status after THA [3, 5]. Postoperative hip pain and functional status were therefore studied in a large cohort of THA patients over a follow-up period of 15 years.

Overweight and obesity are often associated with a variety of additional health problems [13, 14] that may secondarily affect physical function. Furthermore, degenerative joint diseases have detrimental effects on other weightbearing joints and may thus severely affect mobility. The strengths of this study include a possible generalization of the results based on the multi-center nature of the evaluation and the large number of patients and clinical follow-up examinations over a long period of time. Furthermore, the multivariate approach in analyzing the data allowed accounting for effects of confounding factors associated with both outcome and BMI. We therefore consider the results to be applicable to a broad range of patients, irrespective of their age, gender, diagnosis, and factors related to surgical procedures and implants.

Our data support the findings of other studies stating that the probability of developing osteoarthritis with resulting THA is significantly increased in obese patients $[8,10,15$, 16]. Interestingly, obese patients need THA younger than normal weight patients in the diagnostic groups of osteoarthritis, dysplasia, and inflammatory arthritis, but not for fractures. The older age at THA for the diagnostic group of fractures for obese patients may also indicate some preventive effects of obesity, possibly associated with lower levels of physical activity and lower incidence of osteoporosis in such patients. These findings support the hypothesis of Taylor et al. [17], who found a positive correlation between low BMI and increased risk of femoral neck fractures.

There exists only one recent study comparing pain reduction after THA in an obese patients group (BMI $>30$, $n=89)$ against a non-obese patients group (BMI $<30, n=99)$ [18] with no statistical difference after a mean follow-up of 14.5 years. The authors found a complete and long-lasting relief of pain for $70-80 \%$ of all patients. This was irrespective of their preoperative BMI over the entire follow-up period of 15 years. High BMI is therefore an irrelevant prognostic factor for postoperative pain relief. The results confirm the fast alleviation of pain after surgery and the high efficacy of THA in therapy and rehabilitation of disabling disorders of the hip joint.

Furthermore, to our knowledge, this is the first large cohort study showing that high preoperative BMI is associated in an almost perfect dose-effect relationship with decreased ambulation during the entire follow-up period. Maximal outcomes for ambulation (walking without support and climbing/descending stairs) of obese patients were consistently $10-20 \%$ below normal weight patients (Figs. 1 and 2). The data show that peak postoperative walking capacities are reached only 2 to 3 years after THA and remain on a plateau until year 5 . No such plateau phase is seen for climbing and descending stairs, most likely because of the fact that climbing or descending stairs is a less demanding task than walking for more than $1 \mathrm{~h}$. Furthermore, there are no indications of delayed postoperative mobilization in the overweight or obese patient group or of differences in the course of loss of mobilization with increasing postoperative time.

Differences in hip flexion range between BMI groups are less compelling than outcomes directly related to ambulation, and there is no consistent dose-effect relationship after postoperative year 7. It appears therefore that detrimental effects of high BMI on physical function are not directly linked to the biomechanical functionality and flexibility of the hip joint itself, but to the overall agility and mobility of patients. This impression is consistent with the findings regarding the ability to put on shoes and socks, where obese and overweight patients have consistently poorer outcomes during the entire follow-up period, although unimpaired hip flexion range is a prerequisite for putting on shoes and socks.

It can be argued that the overall physical performance of overweight and obese patients is already generally poor before THA and that postoperative functional improvement is regained only in relation to the preoperative status. However, according to the results of this study, BMI is a significant factor associated with poor functional outcome that could be influenced preoperatively [19]. Furthermore, loosing weight has numerous other health benefits, including fewer perioperative complications [20]. On the other hand, it has to be stressed that the most important goal of implanting an artificial hip joint, which is pain reduction, is accomplished in obese patients similarly as in the normal weight group. These facts might warrant some additional recommendations given to patients by physicians before THA, to reduce perioperative risks and improve postoperative outcome quality.

\section{Conclusion}

Overweight and obesity, in particular, are modifiable risk factors that not only play a deleterious role in the pathogenesis of osteoarthritis, but also affect physical outcome after THA. It is therefore important that surgeons inform patients about the negative consequences of high 
preoperative bodyweight on restoring physical function after THA and that they emphasize pre- or postoperative weight control programs. On the other hand, it has to be stressed that THA is equally efficient for pain relief in all BMI groups.

\section{References}

1. Flugsrud GB, Nordsletten L, Espehaug B, et al. The impact of body mass index on later total hip arthroplasty for primary osteoarthritis: a cohort study in 1.2 million persons. Arthritis Rheum. 2006;54(3):802-7.

2. Perka C, Paul C, Matziolis G. Factors influencing perioperative morbidity and mortality in primary hip arthroplasty. Orthopäde. 2004;33(6):715-20.

3. Braeken AM, Lochhaas-Gerlach JA, Gollish JD, et al. Determinants of 6-12 month postoperative functional status and pain after elective total hip replacement. Int J Qual Health Care. 1997;9(6): 413-8.

4. Young NL, Cheah D, Waddell JP, et al. Patient characteristics that affect the outcome of total hip arthroplasty: a review. Can J Surg. 1998;41(3):188-95.

5. Stickles B, Phillips L, Brox WT, et al. Defining the relationship between obesity and total joint arthroplasty. Obes Res. 2001;9(3): 219-23.

6. Paterson D. The International Documentation and Evaluation System (IDES). Orthopedics. 1993;16(1):11-4.

7. Wendelboe AM, Hegmann KT, Biggs JJ, et al. Relationships between body mass indices and surgical replacements of knee and hip joints. Am J Prev Med. 2003;25(4):290-5.

8. Karlson EW, Mandl LA, Aweh GN, et al. Total hip replacement due to osteoarthritis: the importance of age, obesity, and other modifiable risk factors. Am J Med. 2003;114(2):93-8.
9. Gelber AC. Obesity and hip osteoarthritis: the weight of the evidence is increasing. Am J Med. 2003;114(2):158-9.

10. Marks R, Allegrante JP. Body mass indices in patients with disabling hip osteoarthritis. Arthritis Res. 2002;4(2):112-6.

11. Sturmer T, Gunther KP, Brenner H. Obesity, overweight and patterns of osteoarthritis: the Ulm Osteoarthritis Study. J Clin Epidemioly. 2000;53(3):307-13.

12. Perka C, Labs K, Muschik M, et al. The influence of obesity on perioperative morbidity and mortality in revision total hip arthroplasty. Arch Orthop Trauma Surg. 2000;120(5-6):267-71.

13. Kenchaiah S, Evans JC, Levy D, et al. Obesity and the risk of heart failure. N Engl J Med. 2002;347(5):305-13.

14. Calle EE, Rodriguez C, Walker-Thurmond K, et al. Overweight, obesity, and mortality from cancer in a prospectively studied cohort of U.S. adults. N Engl J Med. 2003;348(17):1625-38.

15. March LM, Cross MJ, Lapsley H, et al. Outcomes after hip or knee replacement surgery for osteoarthritis. A prospective cohort study comparing patients' quality of life before and after surgery with age-related population norms. Med J Aust. 1999;171(5): 235-8.

16. Cooper C, Inskip H, Croft P, et al. Individual risk factors for hip osteoarthritis: obesity, hip injury, and physical activity. Am J Epidemiol. 1998;147(6):516-22.

17. Taylor BC, Schreiner PJ, Stone KL, et al. Long-term prediction of incident hip fracture risk in elderly white women: study of osteoporotic fractures. J Am Geriatr Soc. 2004;52(9):1479-86.

18. McLaughlin JR, Lee KR. The outcome of total hip replacement in obese and non-obese patients at 10 - to 18 -years. J Bone Joint Surg Br. 2006;88(10):1286-92.

19. Parvizi J, Trousdale RT, Sarr MG. Total joint arthroplasty in patients surgically treated for morbid obesity. J Arthroplasty. 2000; 15(8):1003-8.

20. Mantilla CB, Horlocker TT, Schroeder DR, et al. Risk factors for clinically relevant pulmonary embolism and deep venous thrombosis in patients undergoing primary hip or knee arthroplasty. Anesthesiology. 2003;99(3):552-60; discussion 5A. 